\title{
Tense, Perspectival Properties, and Special Relativity ${ }^{1}$
}

\author{
Peter Ludlow \\ Universidade Estadual de Campinas \\ Centro de Lógica, Epistemologia e História da Ciência \\ Campinas, SP \\ Brazil \\ peterjludlow@gmail.com
}

Article info

CDD: 121

Received: 18.11.2016; Accepted: 19.11.2016

DOI: http://dx.doi.org/10.1590/0100-6045.2016.V39N4.PL

Keywords:

Tense

Special Theory of Relativity

Perspectivalism

\begin{abstract}
Tensism is the view that tense is not merely a property of language and the mind (narrowly individuated), but of the world itself. Perspectivalism extends this idea to all perspectival properties be they person (e.g. first person vs. second) or locational (e.g. here vs there). One challenge that perspectivalism faces is the problem of expressing the contents of the beliefs and utterances of persons that are in other perspectival positions. One proposed solution to this problem is to allow for semantic theories that "realign" the expression of contents so that the contents expressed by persons in other perspectival positions can be re-expressed from one's own perspectival position. In this paper I argue that a similar semantic realignment strategy could be deployed in helping perspectivalists generally (and presentists in particular) come to grips with a puzzle raised by the Special Theory of Relativity. In short, the strategy is to realign the expression of contents in another inertial frame so that they are expressed from within your inertial frame. As we will see, the strategy is not puzzle free.
\end{abstract}

${ }^{1}$ Thanks to Emiliano Boccardi for some very helpful comments.

Manuscrito - Rev. Int. Fil. Campinas, v. 39, n. 4, pp. 49- 74, out.der. 2016. 


\section{Tensism and Perspectivalism}

'Tensism', as I noted above, expresses the idea that tense is not merely a property of language and thought, but is also a property that has some further, irreducible, metaphysical standing. One way to express this idea is to say that not merely language and thoughts are tensed, but that facts and/or states of affairs in the world are tensed. Let's call someone who endorses tensism a tenser. Let's call someone who rejects this claim and thinks that reality is untensed a detenser. ${ }^{2}$

According to the detenser, so-called tense operators in natural language should be analyzed in terms of a series of events related by tenseless Spacetime relations - for example, they might be related by the earlierthan/later-than relation. We can think of these events being lined up on a time line (or perhaps the time line is nothing more than the ordering of these events). All of the events on the time line are equally real, from the birth of Portuguese King Carlos I, to the event of your reading this paper, to the birth of the first child in the year 2500. Following McTaggart $(1908,1927)$ we can call this series of events an example of the B-series.

To take a very simple case of a detensing semantics, consider the utterance $\mathrm{u}$, of a sentence having the form 'happen-PAST(E)', where 'E' refers to a particular event and 'PAST' is the past tense morpheme. In this case the semantics might look as follows: 'happen-Past(E)' is true iff (the time of) $\mathrm{E}$ happens earlier than (the time of) $u$. If an event $E$ happens earlier than the time of a particular utterance, then that $E$ stands in such a relation to the utterance event should be true everywhere (and from every perspectival position). ${ }^{3}$

The analysis of tense sketched above is a regimentation in the sense of Burgess (1984); although tensed expressions appear in the object language (here as the morpheme 'PAST'), such expressions do not appear in the metalanguage; they are analyzed away in favor of the earlier-than/later-than relation.

\footnotetext{
2 This usage is not universal. Some would define 'tenser' to include those who think tense is psychological. My definition is not so generous.

${ }^{3}$ This is an oversimplification, as we will see when we get to Special Relativity.
}

Manuscrito - Rev. Int. Fil. Campinas, v. 39, n. 4, pp. 49- 74, out.-dez. 2016. 
The detenser also argues that tense is merely a feature of languages (linguistic tense), or the mind (psychological tense) and that we mistakenly project this feature of natural language (or mind) into our metaphysics. In the tenser's view, on the other hand, that picture has things upside down. Most languages of the world have nothing resembling standard IndoEuropean tense morphology. Other languages rely upon elements like aspect, evidentials ${ }^{4}$, and modals to talk about temporal features of the world. Even in English we don't have a genuine future tense (clearly 'will' is a modal in 'I will eat'), and for that matter our past tense morpheme '-ed' looks a lot like an aspectual marker (presumably indicating perfect aspect).

Now of course we are good at identifying the ways in which different languages express past, future, etc., but there is no common feature of the syntax and morphology of these languages that we are picking up on (since they express temporal notions in radically different ways). In the face of these facts, one begins to suspect that there are temporal features of the world and that different languages of the world devise different strategies for talking about those features. If this is right, then natural language tense may only enter into the picture when we think about how language hooks up with the tensed features of the world.

Why be a tenser? The core motivating reason for tensism has to do with the role that tense (and other perspectival properties) can play in explaining human action and emotion.

Suppose that I am sitting in my office one day, aware that I have an important meeting with my boss at 3:00 o'clock. I might utter (1) under my breath as I shuffle papers and take care of administrative minutia.

(1) I have a meeting with the boss at 3:00 o'clock.

\footnotetext{
${ }^{4}$ Evidentials are grammatical elements that encode the source of the information. So, for example, imagine that English had a suffix '-foo' which, when appended to a verb, indicated that the event in question was seen with one's own eyes (as opposed to via testimony or inference). Then if I say 'John walkfoo', I am saying that I saw John walk with my own eyes. The past tense is presumably inferred from the nature of perceptual reports. Many languages use elements like this, often in complementary distribution with explicit past tense morphology.
}

Manuscrito - Rev. Int. Fil. Campinas, v. 39, n. 4, pp. 49- 74, out.-dez. 2016. 
As I dither about in my office, I realize that the clock on my wall hasn't moved off of 2:30 in a while. Puzzled, I check the clock on my computer. It says that it is 3:00. I double-check the time on-line. I conclude that it is in fact now 3:00 o'clock and I utter (2).

(2) Oh no, I have a meeting with the boss now!

I immediately get up and run to the boss's office.

Arguably, my utterance of (2) reflects a piece of knowledge that my utterance of (1) does not and this additional piece of knowledge played a role in my actions. The thought that I expressed by my utterance of (1) was not enough to get me up out of my chair. It was only by coming to have the thought that I express by my utterance of (2) that I formed the intention to immediately run over to the boss's office.

So far, what I have said is a widely accepted observation. In fact, it falls into line with claims about first person judgments more generally. For example, if I know the meeting is in my office and know I am in my office, I won't get up and go anywhere because I am already where I need to be. But it isn't enough to know the meeting is at a particular spatial location - I need to know I am there!

A.N. Prior (1959) made a similar argument for the case of explaining human emotions. If my root canal dental surgery is on May 1, on May 2 I will be relieved that it is over with. But my relief can't really be characterized as me being relieved that the root canal is earlier than May 2. Why should that matter unless I know it's now May 2 and the root canal is over with; it is in $m y$ perspectival past.

The same holds for anticipatory emotions. On April 30 I may be very nervous and concerned about the root canal operation, but it is hard to make sense of that concern unless I know that tomorrow is the root canal. I know it is in my near future. If I lose track of the date, and not realize it is already April 30, even if I know that the root canal is May 1st I may be much less concerned (here assuming that concern increases as the date approaches).

Interestingly, Prior (1967) extended his analysis of tense to other kinds of perspectival properties. So for example, Prior introduced the notion of spatial

Manuscrito - Rev. Int. Fil. Campinas, v. 39, n. 4, pp. 49- 74, out.-dez. 2016. 
tenses to account for the differences between sentences with 'here' and 'there', and he introduced personal tenses to account for the differences between, for example, sentences with ' $\mathrm{T}$ ' and 'she'.

I don't believe there is harm in talking about spatial and personal tenses, nor do I believe there is any harm in talking about sentences with these constructions as being 'indexical' - the preferred locution among philosophers today. However, I do believe that talking about these phenomena as tenses suggests (and as Prior supposed) that there are primitive tense operators at work, and I believe that talking about indexicals suggests that the so-called indexical pronouns are doing the work. Since I am ultimately breaking with both of these analyses, I am going to instead talk about these phenomena as being perspectival, if only to use a descriptor that is not associated with a particular analysis.

'Perspectivalism', as I use the term, is the idea that facts/states of affairs are tensed by virtue of their being constituted, in part, by perspectival properties. By perspectival properties, I mean properties that are inherently tied to an agent's perspectival position - whether that perspectival position be temporal, spatial, or personal (for example, a first person, egocentric position).

So, for example, I would argue that predicates like 'will be fun' and 'was boring' express temporally perspectival properties. This stands in contrast to a standard view on which we think of these predicates as expressing properties that are aperspectival - for example, simply as the properties of being fun and being boring - and on which we say there is a time t1 earlier than the time of utterance at which some event is boring and a time t2 later than this time at which some event is fun.

This view about perspectival properties also stands in contrast to some views that would count as tensism. For example, one could hold that properties are not tensed but that propositions or events are. On such a view, while the properties of being fun and being a boring are aperspectival, we can slide them into propositions that are perspectivally true. For example: "it was true that there is an event that is boring" and "it will be true that there is an event that is fun."

On my view, tense is not primarily a property of sentences or propositions or events. Rather tense is a feature of the properties that verbs in natural language express. If sentences, propositions, or events are tensed, their being tensed is parasitic on their having constituents that are tensed (perspectival)

Manuscrito - Rev. Int. Fil. Campinas, v. 39, n. 4, pp. 49- 74, out.-dez. 2016. 
properties (or, in the case of sentences, constituents that express tensed properties).

Here is a way to illustrate how tense is a perspectival property. Some events happen before others and we can even imagine a timeline in which the sequence of events is arranged by some before/after relation. That timeline contains quite a bit of information, but it does not tell me what is in my future and what is in my past because to know that I would have to know where $I$ currently am on that timeline. Past and future (at least for me) depend on where I am now embedded in that timeline.

But more than that, once I am embedded in the timeline there will be properties that are inherently perspectival. To see this, think of spatial tenses. When I am embedded in a physical location I may experience something as being in front of me or physically before me. I submit that this experience is not illusory -- it is a property things can have: there is a property of being in front of me, for example. This does not mean that they merely bear some relation to the front of my body or my direction of attention (although they do that too).

To illustrate the way that perspectival properties work I find it helpful to think in terms of video games. Consider the difference between old school 2D games like Mario or Space Invaders and "3D” first person shooters like Halo or virtual worlds like Second Life. In a first person shooter you are immersed in a virtual space and certain virtual objects and agents are represented as being before you.

Perhaps the following can illuminate the contrast. Suppose we have a simple two player video game in which a red avatar fights a blue avatar. In the 2D game you need to know which avatar you are - red or blue - in order to play. (Embarrassingly, I've found myself in more complex video games, losing track of which is my avatar.) In the first person shooter version of this game, however, there is no losing track of who I am. If I see a red player I know that is the enemy. This knowledge rests upon the (simulated) perspectival properties that the video game has afforded me.

Notice that this has nothing to do with the orientation of my avatar in the virtual space. In three dimensional video games like Second Life I can create a perfectly spherical avatar and move in that virtual environment with absolutely no graphical clue as to what is in front of me other than what I see before me. For that matter, I can enter the video game with what amounts to

Manuscrito - Rev. Int. Fil. Campinas, v. 39, n. 4, pp. 49- 74, out.-dez. 2016. 
a point-sized avatar. Something being in front of me is largely a matter of my primary direction of attention. (I may glance to the side from time to time, and still say that the thing I glance at is not in front of me). ${ }^{5}$

The physicist Ernst Mach once related the following story. (1959; 4, n. 1)

Not long ago, after a trying railway journey by night, when I was very tired, I got into an omnibus, just as another man appeared at the other end. 'What a shabby pedagogue that is, that has just entered,' thought I. It was myself; opposite me hung a large mirror. The physiognomy of my class, accordingly, was better known to me than my own.

Philosophers have offered a number of accounts of Mach's plight, but on my view, 'is a shabby pedagogue' and 'am a shabby pedagogue' express different properties. The first predicate is perhaps aperspectival, or if it is perspectival it is a property expressing another's shabbiness - a third person perspective. The second predicate (expressed with 'am a shabby pedagogue') routinely expresses a rather different, first person perspectival property. It is used to express one's own shabbiness. It was this second property that Mach only later came to attribute to himself. ${ }^{6}$ In English we signal the deployment of the first person perspectival property by stressing the first person pronoun: "Oh no, $I$ am the shabby pedagogue." Other languages will stress the verb.

G.E.M. Anscombe (1975) made a very similar claim, only on her view the first person pronoun does no semantic work at all. If she is right, when we have a perspectival property of (or in her terminology, an unmediated concept of), in this case, being a shabby pedagogue, the pronoun is a mere grace note in the way that the pleonastic pronoun 'it' functions in English sentences like

\footnotetext{
${ }^{5}$ Does it then follow that perspectival properties are properties that depend upon conscious agents? I don't see why this should be. There is no reason why simple organisms cannot be sensitive to perspectival properties. What such organisms do need, it would seem, is some way of having directed intentions. I assume that this would include very simple machines as well - for example machines that exploit directional sensors. If you happen to think that intentionality requires consciousness then presumably consciousness is a requirement, but I personally would not sign on to that assumption.

${ }^{6}$ Notice I did not say 'self-attribute'.
}

Manuscrito - Rev. Int. Fil. Campinas, v. 39, n. 4, pp. 49- 74, out.-dez. 2016. 
'it is raining'. I won't be following Anscombe down this path; contemporary linguistics has made a strong case for the presence or (sometimes unvoiced) pronominal elements in these constructions. I do believe however, that Anscombe does us a great service by focusing our attention on the predicates and away from the pronouns, which is where most of the attention has been directed for the past half century.

\section{Communicating across perspectival positions}

In section 1 we touched on the idea that metaphysical tense can be thought of as a kind of perspectival property. I now want to suggest that we can incorporate perspectival properties into a semantic theory by using T-theories capable of "displaying" these perspectival properties, or if you prefer, displaying the sense of temporal expressions (by displaying the sense, you, among other things, display the perspectival property on my view). T-theories are not the only way to accomplish this. If I am right and there are perspectival properties at work, then any semantics that allows perspectival properties could be deployed to the same end. I'm using T-theories at this point in the exposition because they allow me to be neutral on what exactly the T-theory is displaying (psychological objects, abstracta, or properties in the world).

The problem we soon encounter is that when we engage in communication, we of necessity communicate with people in other perspectival positions. So, as noted earlier, we often speak with people in different physical locations. Sometimes, we communicate across time (e.g. by leaving messages) and sometimes we report thoughts and comments made at an earlier time. Unless we are talking to ourselves, we also communicate with other persons, who are, obviously, in different egocentric (perspectival) personal spaces.

A perspectival semantics, given for someone at a different time and place, calls for a readjustment of the form in which the content is expressed. So, for example:

'I am hungry today' as uttered by you yesterday is true today iff you were hungry yesterday

Manuscrito - Rev. Int. Fil. Campinas, v. 39, n. 4, pp. 49- 74, out.-dez. 2016. 
So, to express the content of what you said, I must deploy a different set of expressions than you did.

In this section, my goal is to illustrate how this works. I'll first try to situate the core idea within discussions about the role of sense since Frege, and try to sharpen the resulting thesis. Then I will go into some detail on the mechanics and nature of these cross-perspective communication abilities and the resulting picture of the role of perspectival content that emerges.

Our point of departure is a famous passage from Frege (1956).

If someone wants to say the same today as he expressed yesterday using the word 'today', he must replace this word by 'yesterday'. Although the thought is the same, the verbal expression must be different so that the sense, which would otherwise be affected by the differing times of utterance, is readjusted. The case is the same with words like 'here' and 'there'. In all such cases the mere wording, as it is given in writing, is not the complete expression of the thought, but the knowledge of certain accompanying conditions of utterance, which are used as means of expressing the thought, are needed for its correct apprehension. The pointing of fingers, hand movements, glances may belong here too. The same utterance containing the word 'I' will express different thoughts in the mouths of different men, of which some may be true, others false.

In an influential paper, Perry (1977) argued that Frege erred by trying to identify the sense of a sentence (utterance) with a thought. Perry's thinking was that because 'yesterday' and 'today' have different senses, it follows that 'Today is a fine day' and 'Yesterday is a fine day' must have different senses (since they are composed of different senses). But if I can express the same thought today with an utterance of 'yesterday was a fine day' that I expressed yesterday with an utterance of 'today is a fine day' then thoughts cannot be associated with senses. Different senses are deployed in expressing the same thought so thoughts are not in a one-to-one correspondence with the senses of sentences.

This is also the concern about perspectival properties. Our next step in understanding perspectival properties is to lay out some of the responses to Perry's argument. As we will see, the best response (and the one that I believe Frege favored) has largely slipped through the cracks. Here, it will be useful to begin with an outline of the Fregean project as laid out in Heck (2002).

Manuscrito - Rev. Int. Fil. Campinas, v. 39, n. 4, pp. 49- 74, out.-dez. 2016. 
According to Heck, Frege was committed to the following doctrines.

1a) There can be different Thoughts that "concern the same object" and ascribe the same property to it. For example, the Thought that Superman flies and the Thought that Clark Kent flies are different, even though Superman is Clark Kent.

2a) Sentences of the form $\mathrm{N}$ believes that $a$ is $F$ and ' $\mathrm{N}$ believes that $b$ is $F$ can have different truth-values, even if ' $a$ ' and ' $b$ ' refer to the same object.

3) Sense determines reference ${ }^{7}$

4) The sense of a sentence is what one grasps in understanding it.

5) The sense of a sentence is a Thought.

In Heck's view not all of these doctrines can be maintained. Heck has a proposal about which doctrine needs to be given up, but different philosophers have rejected different doctrines.

Referentialists, for example, reject doctrines (1a) and (2a). They argue that if ' $a$ ' and ' $b$ ' refer to the same object, then ' $\mathrm{N}$ believes that $a$ is $F$ ' and ' $\mathrm{N}$ believes that $b$ is $F$ must have the same truth-value. Similarly, the thought that Superman flies is the same thought as the thought that Clark Kent flies.

Alternatively, Heck proposed that we reject (4) -the idea that there is a single thought associated with the understanding of a sentential utterance. Here is how Heck sets out his idea.

But why do we want to find something to call the meaning? What we (relatively) uncontroversially have are speakers who associate Thoughts with utterances and restrictions upon how the different Thoughts they associate with a given utterance must be related if they are to communicate successfully: to put it differently, we have the fact

\footnotetext{
${ }^{7}$ Heck $(2002$; 3 ) allows that this may be understood in a weak way: "On the weakest interpretation of (3), it speaks of 'determination' only in a mathematical sense: it claims only that senses are related many-one to references."
}

Manuscrito - Rev. Int. Fil. Campinas, v. 39, n. 4, pp. 49- 74, out.-dez. 2016. 
that utterances have cognitive value for speakers, and we have communicative norms determining how the cognitive values a given utterance has for different speakers must be related if we are to understand them. (p. 31)

I take it that Heck's point is that even if we end up entertaining different thoughts (e.g. the speaker has one thought and the hearer comes to have another thought) there are cases in which we might say that is good enough for us to claim that the speaker successfully communicated with the hearer. The view bears some similarity to Davidson's same-saying relation. In this case same-saying is replaced with the idea of "appropriately related" contents.

Another possibility, however, is to reject doctrine (5) - we could break the link between senses and thoughts. This way we could say that different senses are expressed on the different occasions (yesterday and today) but the thoughts are still, somehow, the same. This is clearly a repudiation of a core doctrine of Fregeanism, and one wonders what purpose senses would then serve, if any.

I don't intend to go into detail discussing these options because it seems to me that Heck has left out a critical sixth doctrine assumed by both Perry and Heck in their critique of Frege, and when we make that doctrine explicit we will see a very clear alternative solution path. We can state that doctrine as follows.

6) A sense is intimately tied to its manner of expression, so that the senses of 'Today' and 'tomorrow' remain constant

Clearly this additional doctrine is needed to generate the Perry argument, for Perry assumes that the senses of 'yesterday' and 'today' must remain constant. But it is clear that for Frege this simply cannot be the case. Consider the first sentence of the above passage from Frege again, this time with key points emphasized.

If someone wants to say the same today as he expressed yesterday using the word 'today', he must replace this word by 'yesterday'. Although the thought is the same, the verbal expression must be

Manuscrito - Rev. Int. Fil. Campinas, v. 39, n. 4, pp. 49- 74, out.-dez. 2016. 
different so that the sense, which would otherwise be affected by the differing times of utterance, is readjusted.

In other words, the same thought/sense will be expressed in different ways (using different words!) at different times, in different places, and in different mouths. For example, temporal expressions like 'today' can be used to express or display senses (and thus perspectival properties), but they do not express the same sense (and same perspectival property) on each occasion of utterance. Branquinho (2006) puts the idea as follows.

"Cases where one is dealing with indexical contents are problematic because they often involve some realignment in the linguistic means of expression of a thought - on the part of a given thinker - as time goes by. In other words, there are situations in which the verbal expression of an indexical thought entertained by a thinker at a given time must, at a later time, be readjusted in a certain way by the thinker in order for the thought in question to be then entertained; so that one could presumably say that some attitude held at the earlier time towards the thought in question has been retained by the thinker at the later time, the very same thought being the object of the attitude on both occasions. Naturally, such readjustments are to be thought of as being operated in the linguistic means employed for the expression of the thoughts. It does not make much sense - at least in the light of the picture of content we are assuming - to think of the thoughts as being themselves subjected to any sort of change or realignment."

Evans (1996) appears to be making a similar point, although without the explicit reference to expressions. ${ }^{8}$

"Frege's idea is that the same epistemic state may require different things of us at different times; the changing circumstances force us to change in order to keep hold of a constant reference and a constant thought-we must run to keep still. From this point of view, the acceptance on $d 2$ of 'Yesterday was fine', given an acceptance on $d 1$ of 'Today is fine' can manifest the persistence of a belief in just the way in

\footnotetext{
${ }^{8}$ It could be that Evans is rejecting doctrine (3) - the relation between senses and thoughts, so the senses must change to retain the thoughts, although this seems unlikely.
}

Manuscrito - Rev. Int. Fil. Campinas, v. 39, n. 4, pp. 49- 74, out.-dez. 2016. 
which acceptance of different utterances of the sentence 'The sun sets in the West' can."(308-309)

There are several choice points here. Given that we can express the same thought in different ways, there is an interesting question as to whether one form is more basic. For example, you might think that the core case is the first person perspective, and when we use the second or third person perspective to describe a situation, we are simply describing a first person attitude from another perspectival position. Let's call this Option 1.

Whatever merits Option 1 has going for it in the case of person, it is hard to see why a present tense would be more basic than a future or past tense (our actions can be motivated by future and past events even when the present event is not a factor -- think of Prior's "thanks goodness" case, for example).

You might suppose that there are first person thoughts that only I could have or express - for example, I might express such a thought as "I am hungry now" and I could give the semantics for what I was saying as I said it, so that I could express the solipsistic truth conditions as follows.

(3) My utterance now of 'I am hungry today' is true iff I am hungry today

But the problem with this alleged exclusively egocentric thought is that (pace Heck's rejection of doctrine 4 above) I can always choose to recall that thought, and moreover, I can always tell you what I was thinking. For example, the following day I could say to you 'I was hungry yesterday'. Assuming that you can understand what I said, then there is a semantics for what I said (deployed by you), which looks like this.

(4) Your utterance now of 'I was hungry yesterday' is true iff you were hungry yesterday

One possible conclusion that can be drawn is that cases like (4) show that first person thoughts can have the semantics of second person thoughts, which thereby suggests that they are also second person thoughts. This is a

Manuscrito - Rev. Int. Fil. Campinas, v. 39, n. 4, pp. 49- 74, out.-dez. 2016. 
fairly radical idea, and it is admittedly difficult to get a grip on it. Here is one, I believe flawed, way to put the idea, from Rödl (2007).

We found that, in suitable cases, "Today..." said yesterday and "Yesterday..." said today express the same act of thinking. These cases are fundamental in that, without them, there would be no such thing as an act of thinking expressed by either phrase. And when “...today..." yesterday and "...yesterday..." today express the same act of thinking, then they express the same thought. Therefore, it would be misleading to contrast "yesterday"-thoughts with "today"thoughts; in the fundamental case, a "yesterday"-thought is a "today"thought. What holds of "today" and "yesterday" holds of "I" and "you"...My thinking second personally about you and you receiving my second person thought, thinking back at me second personally, is one and the same act of thinking, an act of thinking for two. But you receive my thought thinking an unmediated first person thought. Hence my "You" addressed at you and your "I" that receives my address express the same act of thinking. This case is fundamental in that, without it, there would be no such thing as thoughts expressed by "You..." and, consequently, by "I...". As "You..." said by me to you and "I..." said by you in taking up my address, express the same act of thinking, they express the same thought. Therefore, it is wrong to oppose second person thought to first person thought. This is a difference in the means of expression, not in the thought expressed. Second-person thought is first-person thought. It is thought of the self-conscious (Rödl 2007; 196-7).

I believe it is clearly an error to call these two events "the same act of thinking," but I think it is at least plausible to say that they are acts that involve the same thought or same thought contents (I don't understand why Rödl thinks he needs to collapse the acts of thinking).

Rödl might have also noted that my first person thought could also be a third person thought. For example, I overhear you say 'I am hungry' and I report this to a friend by pointing at you and saying 'he is hungry'. This seems to be the point made by McDowell $(1996,102)$.

The wider context makes it possible to understand that the first person, the continuing referent of the "I" in the "I think" that can "accompany all my representations", is also a third person, something

Manuscrito - Rev. Int. Fil. Campinas, v. 39, n. 4, pp. 49- 74, out.-dez. 2016. 
whose career is a substantial continuity in the objective world: something such that other modes of continuing thought about it would require keeping track of it. That is a way of putting the gist of Gareth Evans's brilliant treatment of self-identification, which builds on P.F. Strawson's brilliant reading of the Paralogisms" (Mind and World, pp. 102).

Let's call this Option 2: first person thoughts are not exclusively first person thoughts; they are also second person thoughts and third person thoughts. Similarly one could say present tense thoughts are also past and future thoughts (past, present, and future forms being ways of expressing the same perspectival thought at different times.) However attractive this view is for the case of person, it leads to some strange consequences in the case of tense. In particular, it suggests that tensed utterances are all simultaneously past, present, and future, and that seems to lead either to contradiction (as McTaggart argued) or to a view like Fine's (2005) fragmentalism -- the idea that, to avoid contradiction, reality itself must be fragmented.

Option 3 would be to try and relativize the perspectival properties to a context or frame, so that a single thought would be first person from one perspectival position, but second or third from another. Similarly, an tensed thought might be future tensed from one perspectival position but present or past from others.

There is a concern with this view that is parallel to one raised by Williamson (2014) with respect to modals: If you think that contingency is variation in truth value relative to varying assignments to world variables you are betraying a failure to understand what contingency is. Hawthorne (2015) has made a similar point with respect to tense: If you think that change in truth value (e.g. future to present) can be characterized as truth values indexed to times, you don't have a handle on what change is. If this is right, then genuine tense (and genuine perspectival properties) can't be indexed in this way. As we will see in section 3, whether it is right depends upon what our philosophical ambitions are.

There is finally Option 4: The semantics in the context of assessment gets to call the shots, so that whether something is first, second, or third person depends upon the semantics I provide. It would follow that $I$ have first person thoughts, you have second person thoughts, and they have third person thoughts. Let's call this the Chauvinistic Option. The crux of the option is

Manuscrito - Rev. Int. Fil. Campinas, v. 39, n. 4, pp. 49- 74, out.-dez. 2016. 
that the correct characterization (1st, $2 \mathrm{nd}$, or third person) of the perspectival thought depends upon the time and place (and person) of the semantics given. Full stop. It still follows that other people have thoughts with the form of first person thoughts, but those thoughts are in fact second or third person thoughts. The view isn't solipsistic, for it concedes that other people exist and that they share thoughts with me; however, I get to call the shots on the perspectival characterization of the thought (person, place and time). We will return to this option in section 3.

Of course, whichever option we use, matters (in English) are not always as simple as the substitution of 'you' for 'I', 'yesterday' for 'today', and 'was' for 'is'. Sometimes expressions of tensed thoughts (and other perspectival thoughts) appear to be radically different even though they are expressing the very same thought. Other times very different tensed thoughts can be expressed using exactly the same linguistic forms. In many of these cases there is no obvious rule for modifying the description. What is going on in these cases?

In Ludlow (2014) I argued that we don't communicate using fixed languages like English and Portuguese, but rather build microlanguages with our discourse participants. These microlanguages have standard languages as their starting points, but we modify fragments of those standard languages by introducing new terminology and modulating the meanings of existing terms. One helpful way to think about microlanguages is to understand that they are constructed to aid in an account of some agent's psychological states (or the content of what they said) and that micolanguages thereby express theories, constructed on the fly, that encode descriptions of those psychological states. But these are special kinds of theories. They are not theories like the theory of gravity is a theory. These theories are local. They are theories that only involve particular individuals at particular locations. They also involve local interests (i.e. the interests of the discourse participants).

Thinking of attitude reports and content reports as being local theories, the realignment rules give us established ways of expressing the same perspectival theory from different temporal and spatial positions. Thinking of attitude reports and content reports as expressing theories also gives us a natural way of understanding the work that the realignment rules do. What they accomplish is that they preserve the explanatory power of local theories from different perspectival positions.

Manuscrito - Rev. Int. Fil. Campinas, v. 39, n. 4, pp. 49- 74, out.dez. 2016. 
As we saw in section 1, stripping the perspectival content from these theories neuters them, and typically renders them nonexplanatory. As we saw earlier in this section, we want our local theory to express our perspectival position with respect to the event we are reporting on, while perhaps respecting the perspectival position of our audience. The realignment principle then, is that the local theory should be constructed to meet these desiderata. Precisely how we satisfy the principle will depend upon the microlanguage that we construct in order to state the theory.

\section{Perspectivalism and Special Relativity}

So far I've made the case that tense (and other perspectival properties) are needed to explain and understand a number of phenomena, including human action and emotion. I've also shown that we can make reports on contents expressed and believed in other perspectival positions, by expressing those contents from within our own perspectival positions.

Some philosophers believe that perspectival approaches to time and tense are refuted by considerations raised by the Special Theory of Relativity. In this section we will see that the worry is analogous in structure to those raised by reporting on contents in other perspectival positions.

What is the objection raised by the Theory of Relativity? In short, the problem comes to this: In the Special Theory of Relativity, under its standard Einsteinian interpretation, there is no absolute notion of simultaneity. For someone moving past us - let's say at .5 speed of light, what counts as "happening now" will be quite different for them than for us. The temporal order of events will also be different; what is in the future for us may be "in the past" from their perspectival position (from within their inertial frame). (My use of scare quotes will become clear in a bit.)

So far what I have said isn't yet an objection to the perspectivalist. The objection requires an additional premise to the effect that we don't get to be chauvinistic about what is "happening now" - we have no ground to say that our inertial frame is special. And this premise seems fair enough on the face of it; there may be other scientists and other philosophers in other frames of reference and they may rightly ask why we tiny Earth-bound beings get to call the shots on what is "happening now" - especially when it is clear to them

Manuscrito - Rev. Int. Fil. Campinas, v. 39, n. 4, pp. 49- 74, out.-dez. 2016. 
that what we insist is "happening now" is, from their points of view, "in the past" or "in the future." The conclusion we are driven to is that no one's notion of past, present, and future are privileged.

That's the concern in the nutshell. Can it be answered? To get a handle on the problem I'll begin with a discussion of what the detenser will say about all of this, then I will take a look at the best responses for the perspectivalist and in particular the presentist.

Thus far we have talked about the detensed, B-theory of time in terms of a timeline with events stacked up along that timeoline - frozen in place, as it were - ordered by an earlier-than/later-than relation. The Special Theory of Relativity raises questions about this picture, given that, as noted, whether an event is earlier than another depends upon one's inertial frame.

One way to approach this problem would be to have many B-theory timelines - one for each inertial frame - but this doesn't help us to understand the relation between the different inertial frames. The solution that was hit on in physics was to deploy Minkowski Spacetime diagrams. To understand how a Minkowski Spacetime diagram can preserve a static picture of time within the relativistic framework, we can illustrate with a particular example.

In the following diagram we represent the temporal dimension on the vertical $t$ axis and the three spatial dimensions on the horizontal $\mathrm{d}$ axis. ${ }^{9}$ The unannotated 45 degree diagonal lines indicate the light cones for event $\mathrm{A}$, represented by the green dot at their intersection. If A were a light signal (a flash, for example) the distance traveled by that signal would define the outer edge of the forward light cone. The backwards light cone would represent the outer limit of earlier signals that might have arrived at A. Let's say there is an observer o, where the ct line represents the temporal history of o through Spacetime. ct' indicates the history of another observer o' moving past $\mathrm{O}$ at a relative speed of $.5 \mathrm{c}$ (where c, of course, is the speed of light). B is an independent event. We can think of the line $\mathrm{d}$ as representing "now" for observer o, and d' as representing "now" for observer o'. We can already see that event B is in "the future" for observer o and "in the past" for observer o'. We can also see that A occurs "before" B for observer o, but A occurs “after" B for observer o'. (Don't worry, I'm going to explain the scare quotes soon.)

${ }^{9}$ Obviously, three spatial dimensions are being represented in one dimension here.

Manuscrito - Rev. Int. Fil. Campinas, v. 39, n. 4, pp. 49- 74, out.-dez. 2016. 

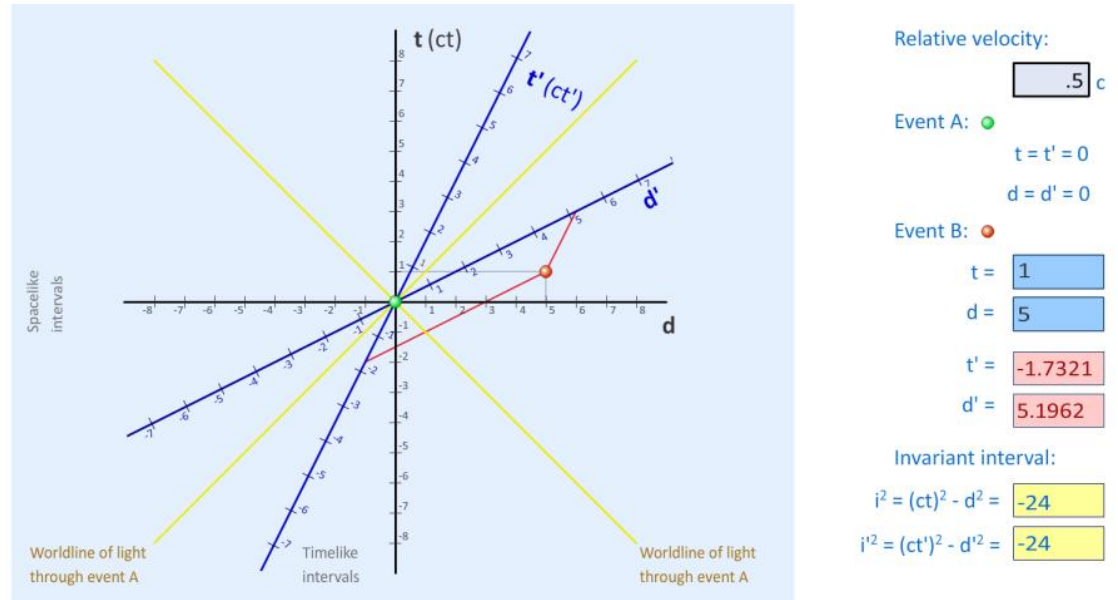

More specifically, we can identify the precise Spacetime location of B for both observers in the following way. For each observer, to fix the time for event B, draw a line through B, parallel to their " $d$ line" (line $d$ for o and $d$ ' for $\mathrm{o}$ '). The point at which that line intersects their respective " $t$ line" ( $t$ for $\mathrm{O}$ and $\mathrm{t}$ ' for $\mathrm{o}$ ') fixes the time of event $\mathrm{B}$ for each observer. In the inertial frame for $\mathrm{o}$, this is pretty simple because $\mathrm{d}$ is horizontal. That line intersects $\mathrm{d}$ at time 1 (one unit in the future). For observer o' we follow the same procedure, now drawing a line through $B$ parallel to d'. In this instance the line intersects t' at -1.7321 (-1.7321 units "in the past"). ${ }^{10}$

We proceed similarly for spatial position (distance from A). In this case we draw a line through $B$ parallel to the $t$ axes, yielding $d=5$ for observer $\mathrm{o}$, and d' $=5.1962$ for observer o'.

For the four-dimensionalist detenser, the diagram effectively encodes the relative Spacetime position of all events for each inertial frame.

For the four-dimensionalist tenser matters are not so different. One merely needs to annotate the Minkowski diagram with perspectival properties. So, for example, for observer o events happening now would consist of events

${ }^{10}$ Here I am relying on the Interactive Minkowski Diagram program of Kristian Evenson at http://www.trell.org/div/minkowski.html (last accessed Oct. 6, 2016). The calculations are based on the inverse Lorentz transformations.

Manuscrito - Rev. Int. Fil. Campinas, v. 39, n. 4, pp. 49- 74, out.-dez. 2016. 
located along d, events that will happen would be those events "north" of d, and events that have happened would be those events located "south" of d. For the observer in inertial frame ct', the story would be analogous, with d' substituted for $\mathrm{d}$.

This story of course requires that we take notions of future and past to be relative to an inertial frame, and this trades on the idea that we are thinking of tense as involving an index to a frame, but in section 2 we saw concerns about that view -- concerns raised by Williamson and Hawthorne. But these concerns, I believe, only become a factor if we rejeect four-dimensionalism and insist on some strong notion of "genuine change.".

One consequence of four-dimensional tensism, of course, is that when someone in a different inertial frame uses the term 'now' it has a different content than when we use the term, but there is no harm in this. This was already the case for individuals uttering the term 'now' at different times within the same inertial frame. It is not a great conceptual leap to suppose that the same thing is true across inertial frames.

One might think that the tense system is part of our cognitive psychology and could not possibly represent some feature such as inertial frame, given that we surely did not evolve in an environment in which relativistic corrections were critical for our survival. I understand the concern, but I believe that it rests upon a view of cognitive science and mental representations that I resisted in Ludlow (2011; section 5.3) - it relies on a kind of Cartesian picture of mental states and a correlative view that computational states in particular are indifferent to their environmental embedding. In my view, the syntactic states of a computational system can depend upon its embedding circumstances. Whether something is an adder or a quadder ${ }^{11}$ can depend upon environmental embedding, and in Ludlow (2011) I even suggested that whether a computational system represents something as a name or a description may depend upon environmental embedding as well.

The kind of environmental sensitivity being called upon now is substantially less robust. The idea is that one should think of the logical form

11 An example, from Kripke (1982), of something that appears to be an adder but only adds up to a certain quantity $n$ after which it returns the value 57.

Manuscrito - Rev. Int. Fil. Campinas, v. 39, n. 4, pp. 49- 74, out.-dez. 2016. 
of our tensed expressions as containing (at most) a parameter or index for inertial frame. In this case the idea would be that when we say something was the case, we are saying it was the case with respect to $i$, where the value of $i$ is fixed by the inertial frame. This feature did not need to evolve gradually as the result of evolutionary tinkering, but simply falls out from the fact that we live in the kind of relativistic world that we do.

This approach has a lot going for it, I believe. For one, as noted, it is the natural extension of the approach we took to perspectival properties. The same expression type, produced at different times and places (and now inertial frames), expresses different perspectival properties. It is parallel to Option 3 that we discussed in section 2 , in which a thought could be first, second or third person depending on perspectival position. The approach preserves all the advantages of perspectivalism while seamlessly integrating perspectivalism with the Special Theory of Relativity.

However, if we want to defend presentism (a view according to which there are no future or past events), things get more interesting. Clearly, in this case, one has to rethink what the Minkowski Spacetime diagram is representing.

To keep things simple initially, let's consider a Minkowski Spacetime diagram for the case of a Newtonian, non-relativistic world. In this case we can say that the positions in the backwards light cone represent general propositions concerning what has happened, and the positions in the forward light cone represent general propositions concerning what will happen. That is, they are graphical representations of all the true claims of the form "... was true when/before ... was true" and "... will be true when/after .... will be true", where the elided material is filled in by e-type temporal anaphors, following the account I gave in Ludlow (1999). As in my account of e-type temporal anaphora, we need to deploy a non-B-theoretic notion of 'before' and 'after'. ${ }^{2}$ The distances backwards or forwards for various event descriptions would depend upon the orderings established by these relational tenses. (If $\mathrm{A}$ was true before $\mathrm{B}$ was true and $\mathrm{B}$ was true before $\mathrm{C}$ was true then we establish an ordering in the backwards light cone where $\mathrm{A}$ is deeper than B which is deeper than C.)

12 This is even more complicated than it sounds, but for the moment let's suppose that ' $\mathrm{A}$ is before $\mathrm{B}$ ' is understood as some disjunction of claims like 'A was past when $\mathrm{B}$ was present' or 'B will be future when $\mathrm{A}$ is present'.

Manuscrito - Rev. Int. Fil. Campinas, v. 39, n. 4, pp. 49- 74, out.-dez. 2016. 
Things get particularly interesting for the presentist when we consider the Minkowski diagrams for the relativistic cases. Again, we would say that the different forward and backwards light cones represent general propositions, but in this case they represent general propositions that were or will be true relative to an inertial frame.

On the one hand this is not really more problematic that the story told for four-dimensional tensism, but on the other hand many presentists may not care for the idea. Here is the problem. Most presentists would like to say that there is something special about our present - that there is one and only one present and that is what we are experiencing. So what then does it mean to say that there are different "presents" corresponding to different inertial frames?

It is a genuine problem, for a presentist philosopher in another inertial frame may right now (right now with respect to our inertial frame) be arguing that events happening where our Spacetime location is (e.g. the event of you reading this sentence right now) "are past" and so "do not exist." Let's say that in the inertial frame of this philosopher, you "have ceased to exist". Another presentist philosopher in yet another inertial frame might be arguing right now (simultaneously with respect to our inertial frame) that you and the event of your reading this sentence are well "in the future." Meanwhile a presentist here is arguing that neither of those other two presentist philosophers currently exist. So who is right? Which presentist philosopher gets to exist?

There is really only one option for the true presentist here, as far as I can tell, and that is to go for a version of Option 4 that we discussed in section 2 -- the chauvinistic option in which my (in this case our) semantics gets to call the shots. On that view, the presentist philosophers in other inertial frames are not saying that we don't exist; they are saying something else -- perhaps that we don't "schmegzist", because, recall, their tensed predicates in their mouths don't mean the same thing as our tensed predicates in our mouths. ${ }^{13}$

\footnotetext{
${ }^{13}$ This talk of schmegzistence needs to be tightened up a bit, for the presentist can't say that there are currently observers in other inertial frames that have the property of being schpresentists. Some of those observers may not yet exist or have ceased to exist. Strictly speaking, one has to say that there were (or will be) schpresentists who claimed (will claim) that everything that schemgzisted (will schemgzist), schmegzisted
}

Manuscrito - Rev. Int. Fil. Campinas, v. 39, n. 4, pp. 49- 74, out.-dez. 2016. 
What they are saying isn't wrong, because they aren't really saying we don't exist. Of course, it also follows that they aren't really presentists -- they are "schpresentists"! 14 Similarly when they said/will say that the event of your reading this sentence 'will happen' or 'was the case', what they meant/will mean is that it is happening now (that is, they meant/will mean what we mean when we now say 'it is happening now').

I hope you can see how the structure of these moves mirrors what we said about perspectival properties and the "realignment" strategies for reporting them that we discussed in section 2. The question is whether we choose to be chauvinistic about the correct perspectival characterization of those perspectival contents or choose to be ecumenical. What about Option 2, which led to Fine's theory of fragmentalism? In the case of Special Relativity it would mean that each inertial frame would have a different reality to it. Whether this is plausible or not on the face of it, Hofweber and Lange (2016) have argued that it fails to account for the relations holding between inertial frames -- relations captured by our Minkowski diagrams.

Returning to Option 4, you may wish to object that there is something fishy going on here. How could it be that an observer o' in inertial frame ct' can look at the Minkowski Spacetime diagram, see the position of event B south of the d' line, utter the words 'that event was -1.7321 in the past' and thereby be saying that the event is happening now? Should we not charitably translate o' as saying that the event was -1.7321 in the past for o'?

The presentist will initially want to resist this formulation because it looks like there is a reference to (or a claim of existence of) some past event, but let's suppose we have some appropriate presentist gloss of this language (etype temporal anaphora, for example). The more serious objection is that the presentist will want to resist the locution "in the past for o'," for that locution is trading on a specialized tenseless notion of "past" - it is merely talking about a B-theoretic position with respect to o'. It is invoking a time-indexed predicate analogous to true-in-a-world and true-at-a-time; in this case it is true-in-a-frame and it is just as problematic as the other cases of indexed perspectival properties.

(will scmegizst) then (when they made their schmegzistence claim). I'm not advocating presentism here; I'm just discussing what it entails.

${ }^{14}$ This consequence was brought to my attention by Emiliano Boccardi.

Manuscrito - Rev. Int. Fil. Campinas, v. 39, n. 4, pp. 49- 74, out.-dez. 2016. 
At best, the presentist will say, we can say that o' uttered something of the form 'B happened at -1.7321 in the past'. If we want to express the tensed proposition that o' expressed using a genuine tensed predicate, we must gloss ' $x$ happened 1.7321 in the past' as ' $x$ is happening now'. Full stop. In effect, the Minkowski diagram gives us the realignment strategy necessary to express the perspectival contents expressed in other perspectival positions.

Now, someone might object, saying "look, you can see that these events are south of the line d' and of course south of line $d$ is past for us, so isn't south of d' past for those in inertial frame ct'? But the presentist is under no compunction to accept this. First, the presentist will reject a tensed understanding of 'past for us' and 'present for them' - she will reject the frame-indexed language. The presentist need only say that events south of line $\mathrm{d}$ are past, and that contents expressed by o' must be realigned as the diagram indicates. She will simply say that she is giving the best translation of what the speaker in ct' is saying. There need be no suggestion that o' is wrong about anything. o' is entitled to translate the contents of what we say as prescribed by the diagram and her descriptions of the events $A$ and $B$ will be true in her mouth.

Finally, the detenser might object that we are just using a cheap semantic trick to avoid the problem here - we are trying to change the language to erase the alleged problem. It is worth noting, however, that the detenser's position and understanding of the Minkowski diagrams rests heavily on the operational (and B-theoretic) definition of 'simultaneity' given by Einstein. There is nothing wrong with that. It is a perfectly legitimate account of the meaning of 'simultaneity', just as there are technical definitions of 'work' in classical physics. The question is whether these technical definitions have semantic reach and whether they supersede the semantic content of our tensed language. The presentist (and the perspectivalist) will presumably want to say no.

Physics (even at the relativistic level) may well need to adopt the view from nowhere. This makes sense, as we want our scientific theories to work well in every part of our world. ${ }^{15}$ The same cannot be said for the one-off local theories that we deploy to explain and understand the actions and emotions of other agents. In this case we must avail ourselves of perspectival properties

15 Not least of which we want our calculations to be simple.

Manuscrito - Rev. Int. Fil. Campinas, v. 39, n. 4, pp. 49- 74, out.-dez. 2016. 
of the sort that physics may have no use for. But it is important to understand that when the perspectivalist deploys expressions like 'is now' or 'exists' she is availing herself of the corresponding perspectival properties. Physics may not have a use for such properties, but it has nevertheless supplied the presentist (and more generally the perspectivalist) with a tool for the realignment of contents across radically different perspectival positions - that is, across different inertial frames.

\section{References}

Anscome, G.E.M. “The First Person,” In S. Gutenplan (ed.) (1975), Mind and Language: Wolfson College Lectures 1974, Oxford: Clarendon Press, 1975, 45-64.

Branquinho, J. “On the Persistence of Indexical Belief.” Paper given to the APA Eastern Division Meeting, Dec., 2005, revised 2006.

Available online at

http://www.joaomiguelbranquinho.com/uploads/9/5/3/8/9538249/persis tence.pdf. Last accessed, Sept. 15, 2016.

Burgess, J. "Basic Tense Logic," in D. Gabbay and F. Guenthner (eds.) (1984), Handbook of Philosophical Logic Vol. 2. Dordrecht: D. Reidel, 89133.

VANS, G. "Understanding Demonstratives." In Collected Papers. Oxford: Oxford University Press, pp. 291-321, 1996.

FINE, K. “Tense and reality". In Kit Fine (ed.) (2005), Modality and Tense: Philosophical Papers. Oxford: Clarendon Press, pp. 261-320.

Frege, G. "The Thought." Trans. by A.M. and M. Quinton, Mind 65, 289311, 1956.

Hawthorne, J. "Comments on Transient Truths: An Essay in the Metaphysics of Propositions (Berit Brogaard).” Inquiry 58, 619-626, 2015.

HECK, R. 2002. "Do Demonstratives have Senses?"” Philosophers' Imprint 2, \#2, <www.philosophersimprint.org/002002/>. Last accessed Sept. 15, 2016.

Manuscrito - Rev. Int. Fil. Campinas, v. 39, n. 4, pp. 49- 74, out.-dez. 2016. 
HOFWEBER, T. and M. LANGE "Fine's Fragmentalist Interpretation of Special Relativity." Noûs, 2016. DOI:10.1111/nous.12150

KRIPKE, S. Wittgenstein on Rules and Private Language. Cambridge: Harvard University Press, 1982.

LuDLOW, P. The Philosophy of Generative Linguistics. Oxford: Oxford University Press, 2011.

Living Words: Meaning Underdetermination and the Dynamic Lexicon. Oxford: Oxford University Press, 2014.

MCDOwell, J. Mind and World. Cambridge: Harvard University Press, 1996.

MACH, E. The Analysis of Sensations. New York: Dover, 1959.

MCTAggarT, J. "The Unreality of Time." Mind 68, 457-474, 1908.

The Nature of Existence. Vol. 2, Cambridge: Cambridge University Press, 1927.

Perry, J. "Frege on Demonstratives," Philosophical Review 86, 474-497, 1977.

PRIOR, A.N. "Thank Goodness That's Over." Philosophy 34, 12-17, 1959. Past, Present and Future. Oxford: Oxford University Press, 1967.

RöDL, S. Self-Consciousness. Cambridge: Harvard University Press.

Williamson, T., 2014. Modal Logic as Metaphysics. Oxford: Oxford University Press, 2007.

Manuscrito - Rev. Int. Fil. Campinas, v. 39, n. 4, pp. 49- 74, out.-dez. 2016. 